\title{
Postcrania of large dissorophid temnospondyls from Richards Spur, Oklahoma
}

\author{
Bryan M. Gee and Robert R. Reisz \\ Department of Biology, University of Toronto Mississauga, 3359 Mississauga Road, Mississauga, \\ Ontario L5L 1C6, Canada
}

Correspondence: Bryan M. Gee (bryan.gee@mail.utoronto.ca)

Received: 27 October 2017 - Revised: 25 January 2018 - Accepted: 14 February 2018 - Published: 22 March 2018

\begin{abstract}
The early Permian karst system near Richards Spur, Oklahoma preserves a diverse assemblage of terrestrial dissorophoid temnospondyls. Here we report the presence of a large-bodied dissorophine dissorophid that is represented by an articulated anterior trunk region, including a partial pectoral girdle, a ribcage characterized by extremely developed uncinate processes, and a rare, completely articulated pes. This represents the first documentation of the clade at the locality. Previously, dissorophids were represented only by the eucacopine Cacops. A complete pelvic girdle with hindlimbs is also referred to Cacops and represents the first material of the posterior trunk region to be described from the genus at Richards Spur. These specimens expand the taxonomic diversity known from the site and provide significant, well-preserved postcranial material that improves the characterization of dissorophid postcranial anatomy.
\end{abstract}

\section{Introduction}

The early Permian karst deposits near Richards Spur, Oklahoma preserve a diverse array of terrestrial dissorophoid temnospondyls. These include three amphibamids (Doleserpeton annectens, Pasawioops mayi, and Tersomius dolesensis), two dissorophids (Cacops morrisi and C. woehri), and one trematopid (Acheloma dunni) (Bolt, 1969; Fröbisch and Reisz, 2008, 2012; Reisz et al., 2009; Polley and Reisz, 2011; Anderson and Bolt, 2013). This dissorophoid assemblage is the richest of any early Permian locality and is possibly the best representation of an early Permian community of terrestrial temnospondyls, but one of the principal challenges confounding a better understanding of this unique occurrence is the paucity of postcranial elements. The scarcity of such el- ements may reflect a taphonomic bias, but it is also likely to be, at least in part, reflective of the historic sourcing of specimens from local collectors and a historic emphasis on both the collection and study of cranial materials by amateur and professional palaeontologists alike. The postcranial skeleton of Doleserpeton is well-characterized (e.g., Sigurdsen and Bolt, 2010), and description of partial, articulated postcrania of C. morrisi is forthcoming (Gee and Reisz, 2018), but the postcrania of all other taxa are poorly known. All of the postcranial material referred to A. dunni (Polley and Reisz, 2011) is isolated and is assigned based on proximity to the holotype skull and similarity to the genotype. Isolated limb elements referred to Cacops sp. and Acheloma sp. were described by Sullivan et al. (2000). Postcrania of Pasawioops, Tersomius, and $C$. woehri are unknown. In addition to the challenges posed by taphonomic and collection biases, attempts to differentiate and to contextualize isolated postcranial elements can also be confounded by conservatism within the clade. This often results in skewed descriptions that focus primarily on cranial elements and sutural patterns. Accordingly, the thorough description of articulated postcrania of large-bodied dissorophids is important for augmenting the record and the understanding of dissorophoid postcrania.

Here we describe a large block that contains the wellpreserved postcrania of two dissorophids (OMNH 73522). The material consists of two skeletal regions: (1) a predominantly anterior trunk region (articulated forelimbs, pectoral girdle, anterior trunk vertebral elements, and ribs) that is also associated with a hindlimb and a pes (Figs. 1-6), and (2) a posterior trunk region (complete pelvic girdle, articulated hindlimbs, disarticulated phalanges) (Fig. 7). The presence of three hindlimbs indicates that at least two individuals are represented. Postcranial synapomorphies permit a referral of 
both individuals to the clade Olsoniformes, which comprises the large-bodied, terrestrial dissorophids and trematopids; any further resolution is more tentative. A large humerus lacking a supinator process allows for the anterior trunk region to be refined to the Dissorophidae, and several features that distinguish the material from Cacops permit a tentative identification as a dissorophine. The posterior trunk region can similarly only be tentatively referred, but the material is identical to that of Cacops and can be differentiated from other olsoniforms on the basis of several features. Although Cacops is one of the better-known dissorophoids from the locality, its characterization has been based mostly on cranial material (Reisz et al., 2009; Fröbisch and Reisz, 2012; Fröbisch et al., 2015) and the anterior trunk region (Gee and Reisz, 2018). The newly described pelvis that we refer to the taxon is informative for expanding the characterized skeletal regions of the Richards Spur eucacopines.

Dissorophines, known almost exclusively from the Texas red beds, have never been previously documented at Richards Spur. Their putative presence expands the dissorophoid assemblage at the locality and adds a new complexity to the community structure that is preserved there. Well-preserved and well-described postcrania are known from only a handful of dissorophid taxa from any locality (e.g., Cacops and Dissorophus from the Texas red beds). Furthermore, the tendency of past workers to simply characterize more isolated or fragmentary postcranial elements as being comparable or identical to Cacops has severely limited comparative studies of dissorophid postcrania. The quality of the material presented here, in conjunction with a thorough, comparative description, provides a broader foundation for future work on dissorophids. In particular, the extremely developed uncinate processes of the ribs and the articulated pes are intriguing and important contributions to our understanding of the ontogeny and taxonomy of olsoniform dissorophoids.

\section{Materials and methods}

\subsection{Materials}

The dissorophoid material spans a single original block (OMNH 73522) that is presently divided disproportionately between two blocks. The larger piece contains material of two individuals: (1) the vast majority of an anterior trunk region (vertebrae, ribs, forelimbs, pectoral girdle) with hindlimbs and pes, and (2) the entirety of a pelvic girdle region (including hindlimbs, probable pes elements) (Sect. 3.1). The smaller piece contains the anteriormost vertebral column (including the atlas and the axis) and a humerus that belong to the same individual as the anterior trunk region on the large block (Sect. 3.2). The material belongs to at least two individuals, as evidenced by three paired hindlimbs (tibia, fibula). This is in agreement with their relative positions, with the pelvic region being upside down and anterior to the anterior trunk region. For clarity throughout the paper, the predominantly anterior trunk region, divided between the two blocks, is referred to as OMNH 73522a, and the posterior trunk region, found only on the larger block, is referred to as OMNH 73522b. Also present between the blocks are a large number of amniote elements, including partial varanopid and captorhinid skulls on the underside, and a captorhinid manus, a captorhinid pes, and a varanopid pes on the same side as the dissorophoid material. These are not described or figured here. Material was prepared using pin vises and air scribes. Figures were prepared using Adobe Photoshop and Illustrator CS6.

\subsection{Locality}

The material is sourced from the early Permian (Sakmarian) karst deposits at the Dolese Brothers Limestone Quarry near Richards Spur, OK, USA.

\subsection{Institutional abbreviations}

OMNH: Sam Noble Oklahoma Museum of Natural History, Norman, OK, USA

\section{Description}

\subsection{OMNH 73522a}

\subsubsection{Pectoral girdle}

The pectoral girdle of OMNH 73522a consists of one cleithrum and two scapulacoracoids (Figs. 1-2). Two olsoniform synapomorphies of the postcrania inform the taxonomic identification: (1) the proportions of the scapulacoracoid (at least three times longer than they are wide) and (2) the dorsal overlap of the scapulacoracoid by the cleithrum. The left girdle is only partially exposed at the dorsal region in lateral profile (Figs. 1-2). From the dorsal margin of the scapulacoracoid, the flat portion of the cleithrum curves anteroventrally to follow the anterior margin of the former, thickening along the posterior margin to form a thin, blade-like ventral extension that continues down the anterior margin of the scapulacoracoid. This ventral process extends nearly to the glenoid, whereas the dorsal blade terminates abruptly just ventral to the curve. The right girdle is fully exposed in posterior profile, with features such as the glenoid, the supraglenoid fossa, and the glenoid and coracoid foramina exposed (Figs. 1-2). No corresponding right cleithrum is present. The fusion of the scapula and the coracoid without an identifiable suture demarcating their original contact is indicative of relative maturity.

The pectoral elements of olsoniforms are highly conserved. Minor variation in proportions (e.g., height of the dorsal blade) and curvature of the margins may exist, but much of the material from which these elements are de- 


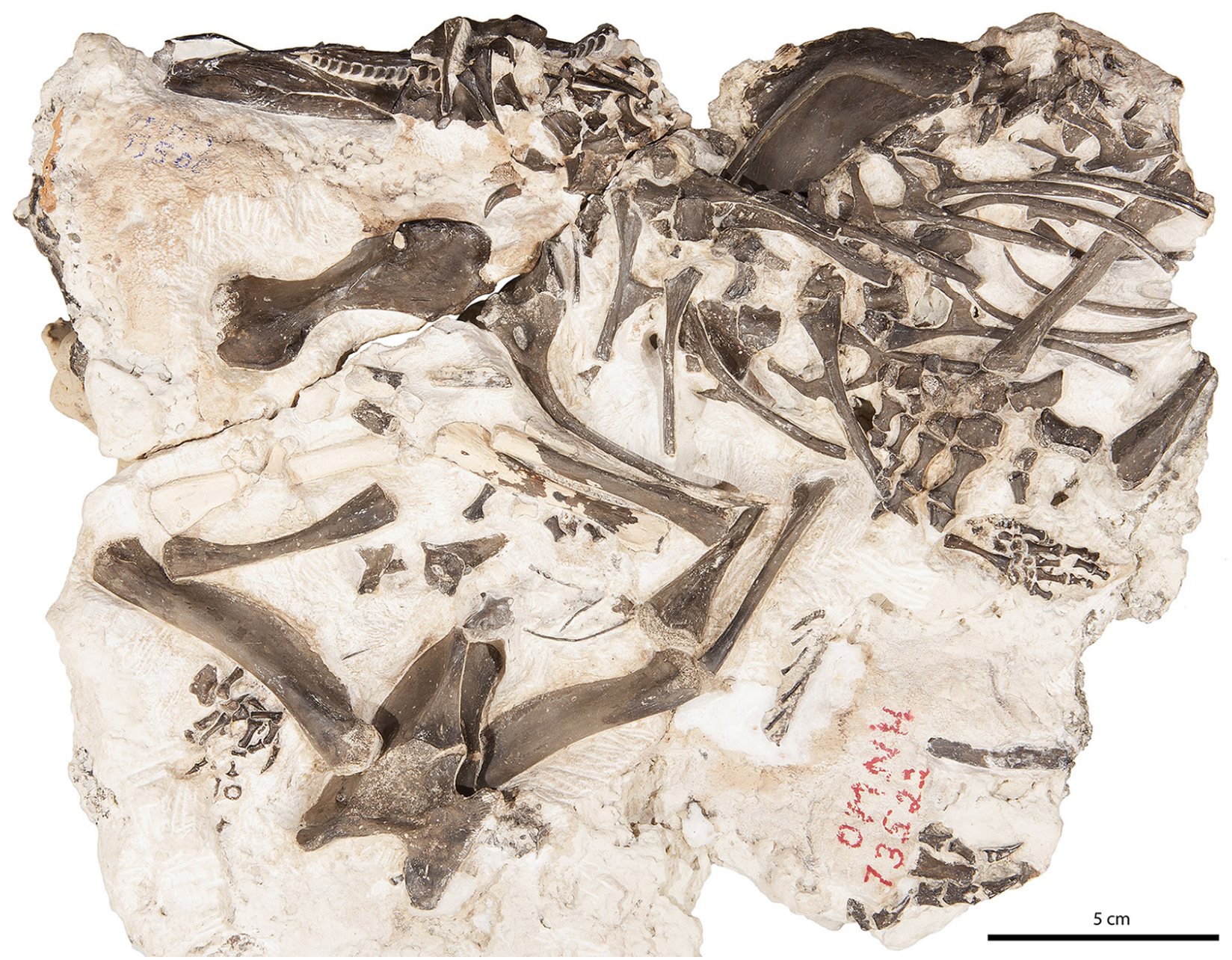

Figure 1. Photograph of new olsoniform specimen, OMNH 73522.

scribed is fragmentary or has been partially reconstructed, particularly in trematopids. Most descriptions of the girdle in other dissorophids feature only a blanket statement indicating marked similarity of the elements to Cacops; this is true for Dissorophus (DeMar, 1968), Scapanops (Schoch and Sues, 2013), Broiliellus texensis (Williston, 1914) and Conjunctio (Case et al., 1913; Carroll, 1964). As a result, the cleithrum and the scapulacoracoid of OMNH 73522a are relatively uninformative for lower taxonomic resolution at this time. It should be noted that the ventral process of the cleithrum of OMNH 73522a is more blade-like, in contrast to the rod-like morphology seen in taxa such as Cacops (Williston, 1910; Gee and Reiz, 2018) and Dissorophus (DeMar, 1968).

\subsubsection{Ribs}

A total of nineteen presacral individual ribs can be identified in OMNH 73522a, many of which are complete (Figs. 12). Nearly all feature prominent uncinate processes (Fig. 4). Ten pertain to the left side of the body, while nine pertain to the right side. The ribs are transversely flattened at the proximal ends such that they are modestly anteroposteriorly long when viewed in lateral profile. The heads are divided into the broader capitulum and the more slender tubercle and are significantly broader than the shaft. They narrow toward the uncinate processes, which are attached at a right angle to the shaft via a thin flange. The processes project posteriorly and then angle dorsally and slightly posteriorly so as to be nearly at a right angle to the proximal head, approximating the shape of the number "four". The thin ventral flange that bridges the shaft to the uncinate process is fairly broad and smoothly curved toward the presumed anterior of the ribcage. It is slightly recessed such that the shaft remains well-defined along the shared contact (Figs. 1-2, 4). It becomes indented along the ventral margin more posteriorly in the column, which does not appear to be a taphonomic artifact, resulting in a more sharply curved posterior margin of the flange. Ventral to the uncinate processes, the shaft becomes cylindrical in cross-section.

The ribs are reasonably informative for excluding some taxa from consideration in identifying this material. At least 


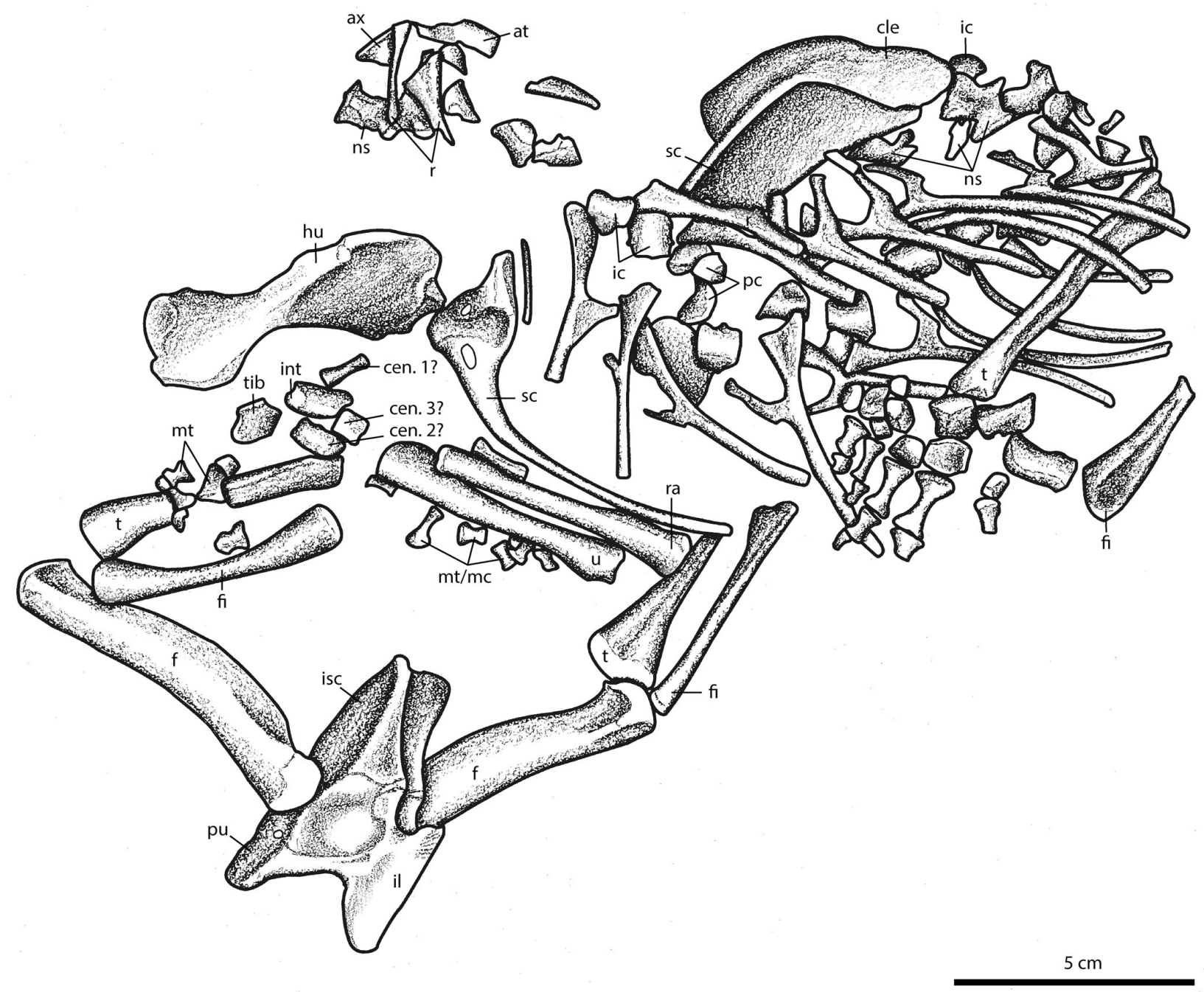

Figure 2. Illustration of new olsoniform specimen, OMNH 73522. As noted in the description, non-temnospondyl elements are also present on this block; these are not figured. Abbreviations: at, atlas; ax, axis; cen, centrale; dt, distal tarsal; f, femur; fi, fibula; fib, fibulare; hu, humerus; i, intercentrum; il, ilium; int, intermedium; is, ischium; mc, metacarpal; mt, metatarsal; ns, neural spine; p, pubis; pc, pleurocentrum; r, rib; ra, radius; sc, scapulacoracoid; t, tibia; tib, tibiale; u, ulna.

in some trematopids, the ribs are flattened blades (Dilkes, 1990; Berman et al., 2011), whereas dissorophids feature cylindrical shafts. Acheloma cumminsi is reported to have some cylindrical ribs, but these are also relatively short in comparison to those of OMNH 73522a (Williston, 1909). The relative expansion of the proximal head compared to the shaft in OMNH 73522a is comparable to Platyhystrix and Cacops (Williston, 1910; Langston, 1953) and dissimilar to other dissorophids (e.g., Broiliellus, Aspidosaurus, Dissorophus) in which it is only slightly expanded (Williston, 1911, 1914; DeMar, 1968). Broad expansion also occurs in A. cumminsi and Ecolsonia (Williston, 1909; Berman et al., 1985). The uncinate processes are also informative; they are not uncommon in dissorophids and were characterized as typical for the family by Berman and Lucas (2003), but among trematopids, they are only known in Phonerpeton (Dilkes, 1990). For most of the taxa in which uncinate processes are known, figures and descriptions are too generic to discern the precise morphology of the processes. For example, figures of Dissorophus (DeMar, 1968: fig. 12), Phonerpeton (Dilkes, 1990: fig. 11), and Aspidosaurus (Carroll, 1964: fig. 17) suggest that these taxa possess little to no flange bridging the process with the shaft and none is described or figured for Scapanops (Schoch and Sues, 2013). A similarly large flange is present in the anterior trunk region of a specimen of $C$. morrisi (OMNH 73206) (Gee and Reisz, 2018). However, the flange is more weakly distinguished from the shaft, and there is no transition in the morphology of the flange over the preserved axial region, in contrast to OMNH 73522a (Gee and Reisz, 2018). 

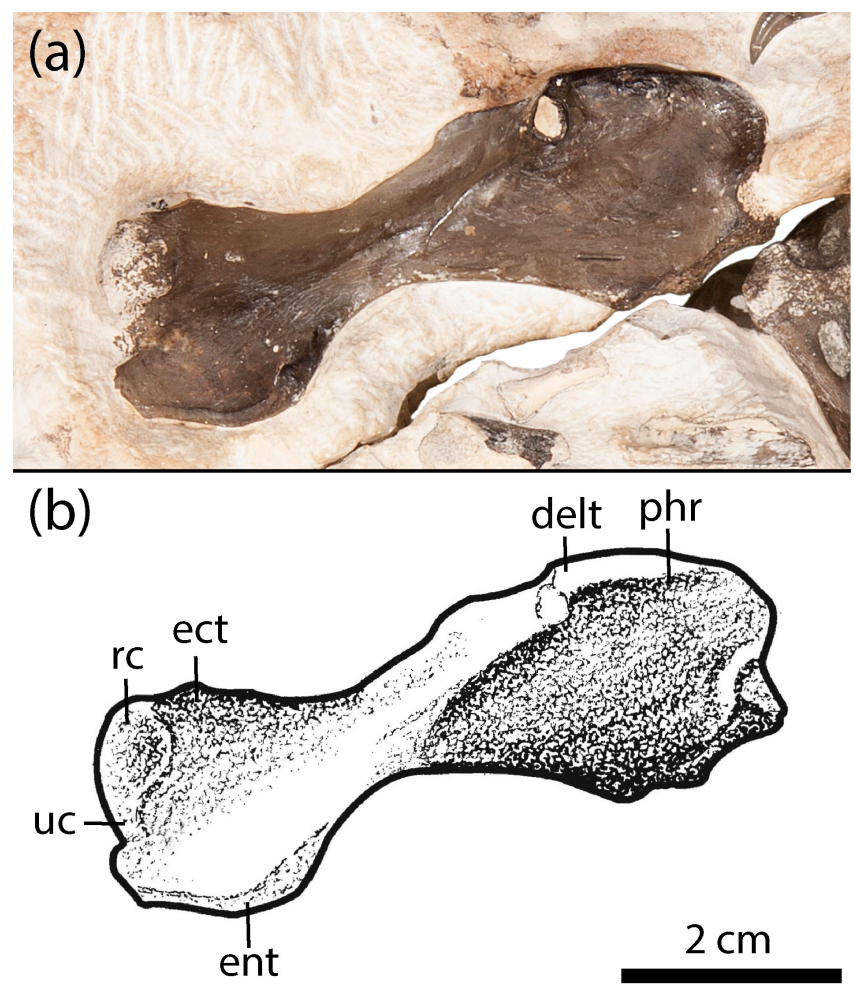

Figure 3. Humerus of new olsoniform specimen, OMNH 73522a. (a) Photograph, (b) illustration. Abbreviations: delt, deltapectoral crest; ect, ectepicondyle; ent, entepicondyle; phr, proximal humeral ridge; rc, radial condyle; uc, ulnar condyle.

\subsubsection{Vertebrae}

Fifteen presacral vertebrae are identified in OMNH 73522a based on the number of intercentra (Figs. 1-2). Three pleurocentra and twelve neural spines (including the atlas and axis) are also present. The atlas consists of two dorsally oriented prongs that frame the dorsally open notochordal canal. The axis, characterized by an anteroposteriorly elongate spine, is inserted between the prongs; it is similar to other vertebrae except in being elongated anteroposteriorly. Most of these elements, particularly the neural spines, are displaced at a variety of angles (e.g., Fig. 5). In most instances, the intercentra are upside down (ventral surface exposed) at the block's surface, but they form a roughly continuous column in which each intercentrum is located adjacent to another two in a reasonable pattern of association. The distribution of the disarticulated neural spines and pleurocentra is entirely random, and most cannot be confidently associated with a particular intercentrum. The presence of the atlas-axis complex, the general articulation of the intercentra, and the close association of elements within the ribcage indicate that all of the vertebrae pertain to the anterior to mid-trunk region. However, their exact position beyond the third vertebra cannot be as confidently identified,
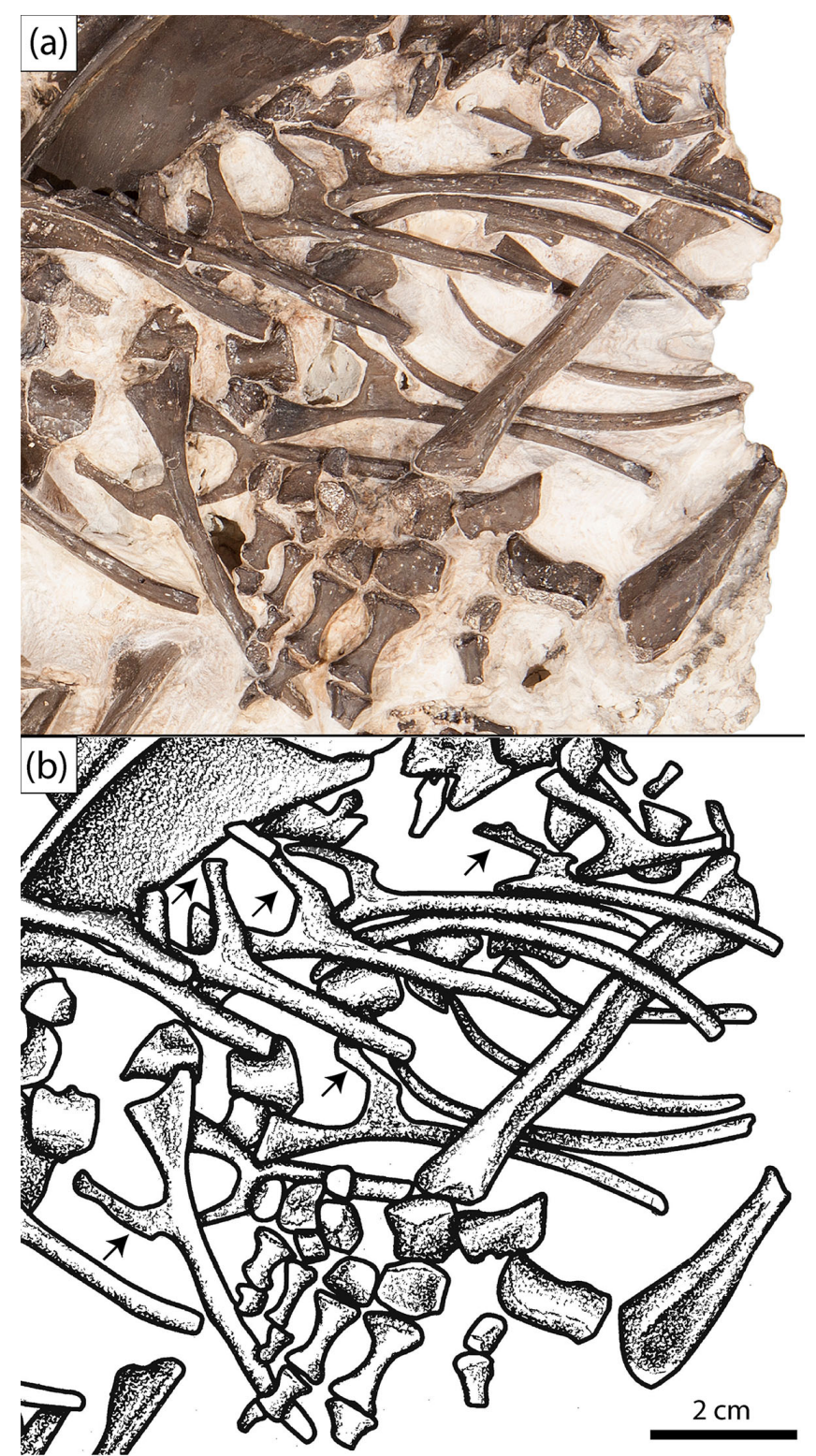

Figure 4. Close-up of the anterior trunk region showing the uncinate processes (subset indicated by arrows) of the new olsoniform specimen, OMNH 73522a. (a) Photograph, (b) illustration.

given the state of disarticulation. The intercentra feature a typical rhachitomous morphology seen in olsoniforms except for Ecolsonia, which features ring-shaped intercentra formed by an incomplete dorsal closure of the notochordal canal (Berman et al., 1985). Only the smooth ventral and lateral surfaces can be visualized. The ventrolateral surfaces are slightly concave. In a few intercentra, the profile of the laterally projecting dorsal apices is visible. The neural arches are typical of rhachitomous temnospondyls, with posteriorly directed postzygapophyses that are obliquely angled ventromedially, anteriorly directed prezygapophyses, and laterally projecting transverse processes. The transverse processes are 


\section{(a)}

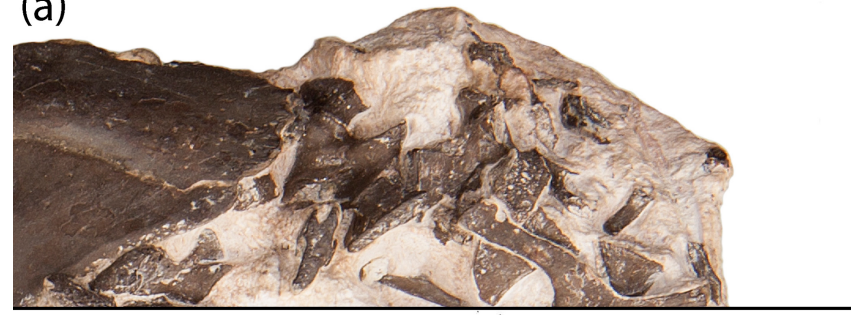

(b)

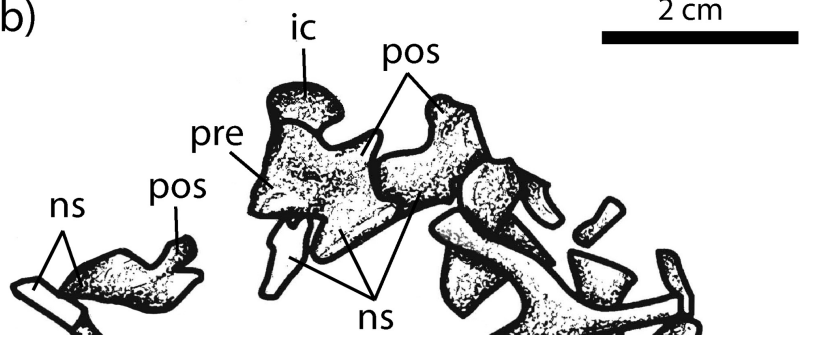

Figure 5. Close-up of the anterior trunk region showing the neural arches of trunk vertebrae of the new olsoniform specimen, OMNH 73522a. (a) Photograph, (b) illustration. Abbreviations: ic, intercentrum; ns, neural spine; pos, postzygapophysis; pre, prezygapophysis.

obscured in most of the arches. The spines are capped by a smooth surface of finished bone (Fig. 5). The ovular facets of the postzygapophyses are visible in several arches (Fig. 5). The arches are conserved among olsoniforms with the exception of variation in the proportions (e.g., hyperelongation in Platyhystrix) and in modifications associated with the vertebra-osteoderm articulation (e.g., Dilkes and Brown, 2007; Dilkes, 2009). Nearly all of the spines feature some degree of uneven lateral thickening that originates around the mid-height of the spine and that continues toward the tip (Fig. 5). There is also an asymmetrical lateral expansion at the tip of the spine that often protrudes toward one side. This protrusion is oriented anteroposteriorly and is relatively thin. In dorsal profile, it is partially separated from the rest of the spine so as to form a posterior incision, presumably to accommodate a ventral flange of the osteoderms (Fig. 5).

The atlas is particularly informative, as it is open dorsally around the notochordal canal, a feature not present in $\mathrm{Ca}$ cops (Williston, 1910) but identified in Dissorophus and Acheloma dunni (DeMar, 1968; Polley and Reisz, 2011). The profile of the cotyle conforms more closely to dissorophids than to trematopids, in which it is proportionately wider. Of the trunk vertebrae in OMNH 73522a, only the spines are of some comparative significance, and a paucity of this region in trematopids further limits their utility. Proportionately tall spines have been suggested to be a dissorophid synapomorphy, but Cacops morrisi and Broiliellus have much shorter spines than other taxa (Schoch, 2012; Gee and Reisz, 2018), as with this specimen, an aspect that may be ontogenetically influenced. The nature of the spine tips of OMNH 73522a is typical of dissorophines, in which incised grooves at the pos- terodorsal margin of the spine are recognized to accommodate ventral flanges of the internal osteoderms (DeMar, 1968; Dilkes, 2009). Furthermore, the finished bone at the tip of the spine supports an interpretation that the osteoderms were attached to the spines via ligaments (dissorophines) rather than by fusion (eucacopines).

\subsubsection{Forelimb elements}

The paired right radius and ulna are assumed to pertain to OMNH 73522a based on the close association with the right humerus and scapulacoracoid (Figs. 1-2). The radius appears to be exposed in posterior profile with the black distal end being directed towards the tibia and being more expanded than the more cylindrical proximal end. Beyond a slight torsion of the shaft and mild expansion of the ends, little more can be said about it. The paired ulna is a piebald-coloured element with its distal end similarly directed toward the putative left tibia. It is exposed mostly in the anterior profile, with the curved margin of the olecranon angled slightly into the block below the radius; the semilunar notch is not exposed. The lateral margin features a slight, inwardly directed extensor keel. The distal end is not appreciably differentiated into the articular facets; a sheer lateral surface at a steep angle appears to be a broken surface. Curvature of the flexor margin appears relatively slight, but the distal end may be partially obscured. The shaft is modestly constricted and slightly torqued.

Comparisons of these forelimb bones are difficult because of a high degree of conservatism in the forelimb of olsoniforms. This has resulted in extremely brief descriptions of the element and illustrations that lack details beyond the contour. The radius of other taxa has often been figured in either extensor or flexor profiles in order to characterize the relative expansion of the ends compared to the shaft, whereas the radius of OMNH 73522a is exposed posteriorly in a less informative profile. The ulna is preserved in the anterior profile, a commonly figured view, but because of the aforementioned brevity of past descriptions, clear differences between that of OMNH 73522a and other olsoniforms cannot be identified.

A right humerus is present in association with the right scapulacoracoid of OMNH 73522a (Figs. 1-3). It is nearly complete, save for minor loss along the fracture plane at the proximal end (Fig. 3). There is no evidence of a supinator process, a characteristic feature of trematopids that significantly informs the taxonomic assignment of the material. The deltapectoral crest and the distally positioned ulnar and radial condyles are well-defined. The entepicondyle descends slightly below the level of the ectepicondyle. A prominent ridge is found at the dorsal margin of the former toward the shaft. The morphology of the element is typical of olsoniforms in having expanded ends that are oriented at approximately an $80^{\circ}$ angle to each other and that are connected by a flattened, constricted shaft.

The humerus is identical to one ascribed to an unnamed taxon from the Texas red beds that was figured by Willis- 
ton (1910: pl. 15, 1a-b), save for a slightly reduced distal extent of the entepicondyle and the ectepicondyle. Unfortunately, without any description beyond noting that it belonged to a new species (Williston, 1910, p. 273) or an associated specimen number (it was stated to be reposited in the University of Chicago collections), it is unclear whether this specimen was ever identified or whether it can be restudied. Probably it was collected from the Clear Fork Group from which Cacops aspidephorus, the main focus of the paper, was collected, but it is not explicitly stated as such. The absence of a supinator process of this mystery humerus and the humerus of OMNH 73522a excludes all trematopids from taxonomic consideration. Differences between described dissorophids pertain mainly to the proportions. The humerus of Cacops features a slightly longer, more cylindrical shaft, a less developed ectepicondyle, and proportionately shorter and broader ends than in OMNH 73522a (Williston, 1910). Of the recognized dissorophid taxa, the humerus conforms well to that of Dissorophus (DeMar, 1968) in proportions and general morphology. That of Dissorophus does appear to be stockier than that of OMNH 73522a, and it is unclear whether the former also possesses the well-defined ridge along the dorsal entepicondylar margin. Little detail can be made out of the humerus in Broiliellus brevis and B. reiszi that would further inform this comparison (Carroll, 1964; Holmes et al., 2013).

\subsubsection{Pes}

A right pes is identified in association with OMNH 73522a on the basis of five digits being present (Fig. 6); all temnospondyls possess a tetradactyl manus. It is mostly articulated and when dislodged, remains in close association with the other elements and relative to the tibia and the fibula, as on the medial side (Fig. 6). Only three of the four large distalmost tarsals (fibulare, tibiale, intermedium, centrale 4) are preserved. A prominent hole is found adjacent to the intermedium and digit 5 , which may be the original position of the fibulare. The most elongate and medially displaced element is centrale 4 . It is rotated about $180^{\circ}$ such that the proximal surface faces distally and lies the closest to the fibula (Fig. 6). It is slightly expanded in thickness proximally. The distal margin is smooth and slightly concave laterally before squaring off at the facet that contacts centrale 2. The lateral margin is slightly oblique. A similarly elongate element adjacent to centrale 2 and closer to the tibia is the intermedium, rotated about $45^{\circ}$ (Fig. 6). The element is markedly wedge-shaped in cross section, being expanded medially toward the smooth surface that contacts the tibia and toward the distal end. The proximal margin is angled where it would have contacted the fibula, while the lateral and distal margins are straight. The lateral margin features a small concavity toward the distal end that separates the facet for the fibulare from that for centrale 4. Dilkes (2015) suggested that this may have been for a perforating artery. The tibiale contacts the tibia but is rotated

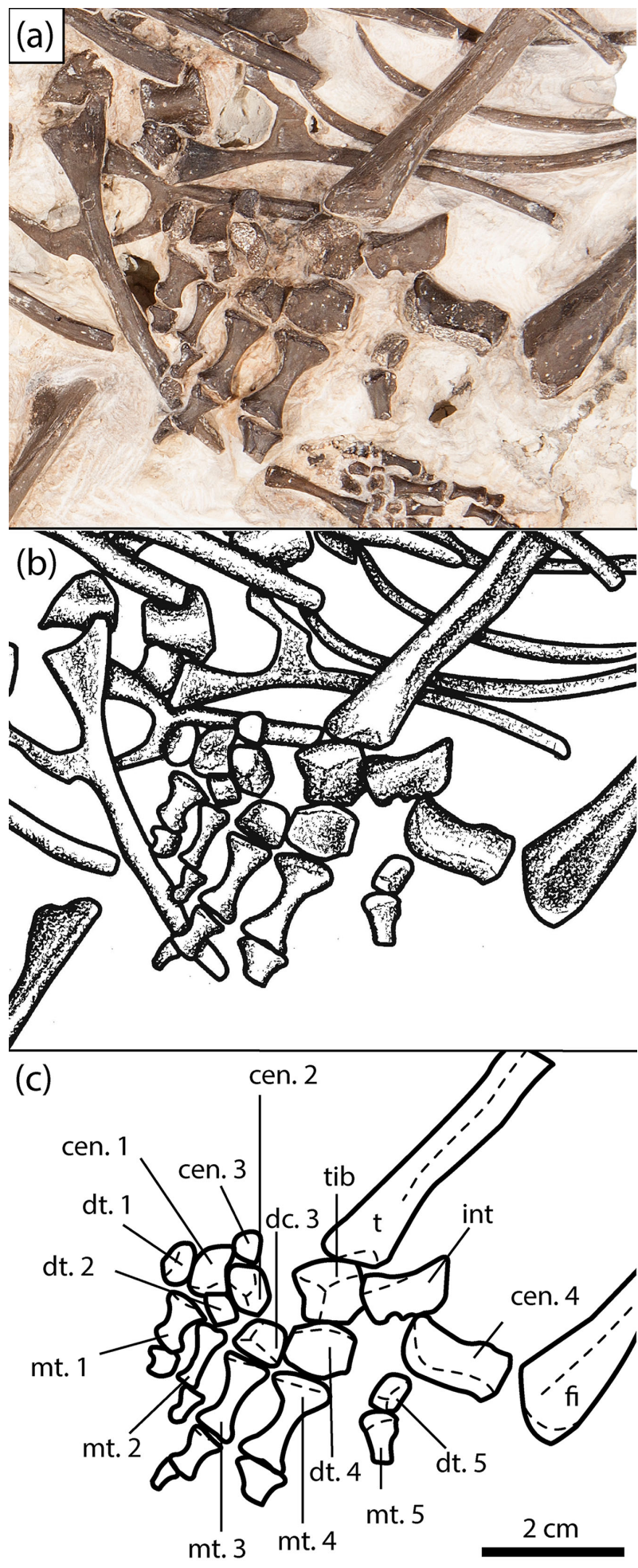

Figure 6. Close-up of the right pes of the new olsoniform specimen, OMNH 73522a. (a) Photograph, (b) illustration, (c) labelled line drawing. Abbreviations: cen, centrale; dt, distal tarsal; fi, fibula; fib, fibulare; int, intermedium; mc, metacarpal; mt, metatarsal; t, tibia; tib, tibiale. 
upside down in position, with the facet for centrale 4 facing medially (Fig. 6). It is blocky and pentagonal in contour. The remainder of the surfaces (proximal, distal, medial) are not exposed.

The smaller, central tarsals (centrale 1 to 3 ) are disarticulated and rotated at the medial region of the pes (Fig. 6). As a result, they are more tentatively identified on the basis of their relative size, which appear conserved among temnospondyls with a well-preserved pes (Dilkes, 2015). Centrale 2 is the largest of the three and is likely to be the most laterally positioned, lying proximal to digits two and three (Fig. 6). It has been rotated such that either the proximal or the distal surface faces outward. This surface appears to have two weakly differentiated facets that likely pertain to the proximal facets for the tibiale and centrale 4. It is generally square and blocky. Centrale 3 is the smallest element and is positioned just proximal to centrale 2, overlying a rib (Fig. 6). Beyond a square shape, little more can be said about its morphology or orientation. Centrale 1 is thus identified as the subtriangular element that divides distal tarsals 1 and 2 (Fig. 6). It also appears to have been rotated about $180^{\circ}$ because the concave, finished medial margin faces laterally. The lateral margin is more gradually curved where it would have contacted centrale 2 and distal tarsal 1.

The distal tarsals are blocky elements of a variable size; distal tarsal 4 is the largest, while the adjacent distal tarsal 5 is the smallest. Distal tarsals 3 and 4 remain articulated with their respective metatarsals, while tarsals 2 and 5 are rotated but remain in place (Fig. 6). Distal tarsal 1 is slightly dislodged laterally. The proximal metatarsals are fairly elongate bones with prominently constricted shafts. They are all complete and articulated, save for metatarsal 5, which is incomplete distally with the rest of the digit. The distal metatarsals become increasingly stockier with shorter shafts, and the distalmost ones are lost in most positions except for digit 4. Distal metatarsal 2 is slightly angled downward into the block, hence why it appears slenderer than that of the first position.

Even though dissorophoids account for a majority of the small set of well-known temnospondyl mesopodia, the pes of OMNH 73522a can only be directly compared to Acheloma cumminsi and Dissorophus. Parts of the manus and/or pes are known in some amphibamids (e.g., Eoscopus, Doleserpeton, Platyrhinops), but these are less complete than that of OMNH 73522a and are characterized by significantly less differentiation of the constituent elements (Daly, 1994; Clack and Milner, 2010; Sigurdsen and Bolt, 2010). The pes of OMNH 73522a can be differentiated from the complete pes of A. cumminsi (Dilkes 2015: fig. 5) by a more elongate intermedium, a more equant, pentagonal tibiale, a more equant centrale 1, and increased constriction of the shafts of the proximal metatarsals. Differences between OMNH 73522a and the partial pes of Dissorophus (Dilkes, 2015: fig. 7) include a more elongate intermedium and centrale 4 and a larger, more equant tibiale. Because the pes is so poorly known for most temnospondyls, let alone for dissorophids, intraspecific variation due to ontogeny and interspecific variation due to taxonomy are difficult to parse out. The phylogenetic characters concerning the tarsus that were added by Dilkes (2015) are useful only for differentiating higher order clades within Temnospondyli, not for further taxonomic resolution within Olsoniformes (see Dilkes, 2015: fig. 12 for distribution of carpal and tarsal characters).

\subsection{OMNH 73522b}

\subsubsection{Pelvic girdle}

The pelvic girdle of OMNH 73522b consists of the posteriorly directed ischium, the dorsally expanded ilium, and the anteriorly directed pubis (Fig. 7). Two synapomorphies support the referral of this individual to Olsoniformes: (1) an iliac shaft that is shorter than it is long, and (2) a vertically oriented iliac shaft (Schoch, 2013; Dilkes, 2015). The acetabulum is modestly deep and semicircular in outline. The anterior margin, formed by the pubis and the ilium, is thicker and more elevated than the posterior margin, formed by the ischium and the ilium. The latter margin features a supracetabular notch that partially divides the elements; the dorsal margin of the pelvis is kinked at this notch. Ventral to the notch is a robust lateral expansion of the ischium. The ventral margin of the acetabulum is unbordered and only slightly higher than the floor of the socket. The dorsal margin is formed entirely by the ilium and thickens dorsolaterally to merge with the iliac crest. The crest is double-headed, more elongate anteriorly, and features striations dorsally for muscle attachment. The pubioischiadic plate descends ventromedially at approximately a $45^{\circ}$ angle. Ventral to the acetabulum on the plate are the obturator foramen and a smaller, more dorsally facing foramen.

The pelvic girdle is highly conserved in olsoniforms and differs primarily in relative proportions. Because the pelvis is rare and frequently damaged (especially the iliac crest), slight differences, such as the anteroposterior extent of the iliac crest, render any interpretations somewhat tenuous. Beyond proportions, three qualitative observations differentiate olsoniform girdles: (1) the contour of the dorsal margin of the pubis, (2) the angle of descent of the pubioischiadic plate, and (3) the contour of the dorsal margin of the ischium at the supracetabular notch. The dorsal margin of the pubis in OMNH 73522b is mostly straight and then curves inward toward the anterior margin. The plate descends at a slanted angle, and there is a prominent outward kink at the notch. These features are also seen in Cacops aspidephorus (Williston, 1910). In Acheloma, the pubioischiadic plate is nearly vertical, there is no kink at the supracetabular notch, and the dorsal margin of the pubis first bows outward before transitioning into the concavity seen in $\mathrm{Ca}$ cops (Olson, 1941; Polley and Reisz, 2011). In Ecolsonia, the concavity of the dorsal margin of the pubis is more pronounced and originates higher up, the plate is nearly vertical, 

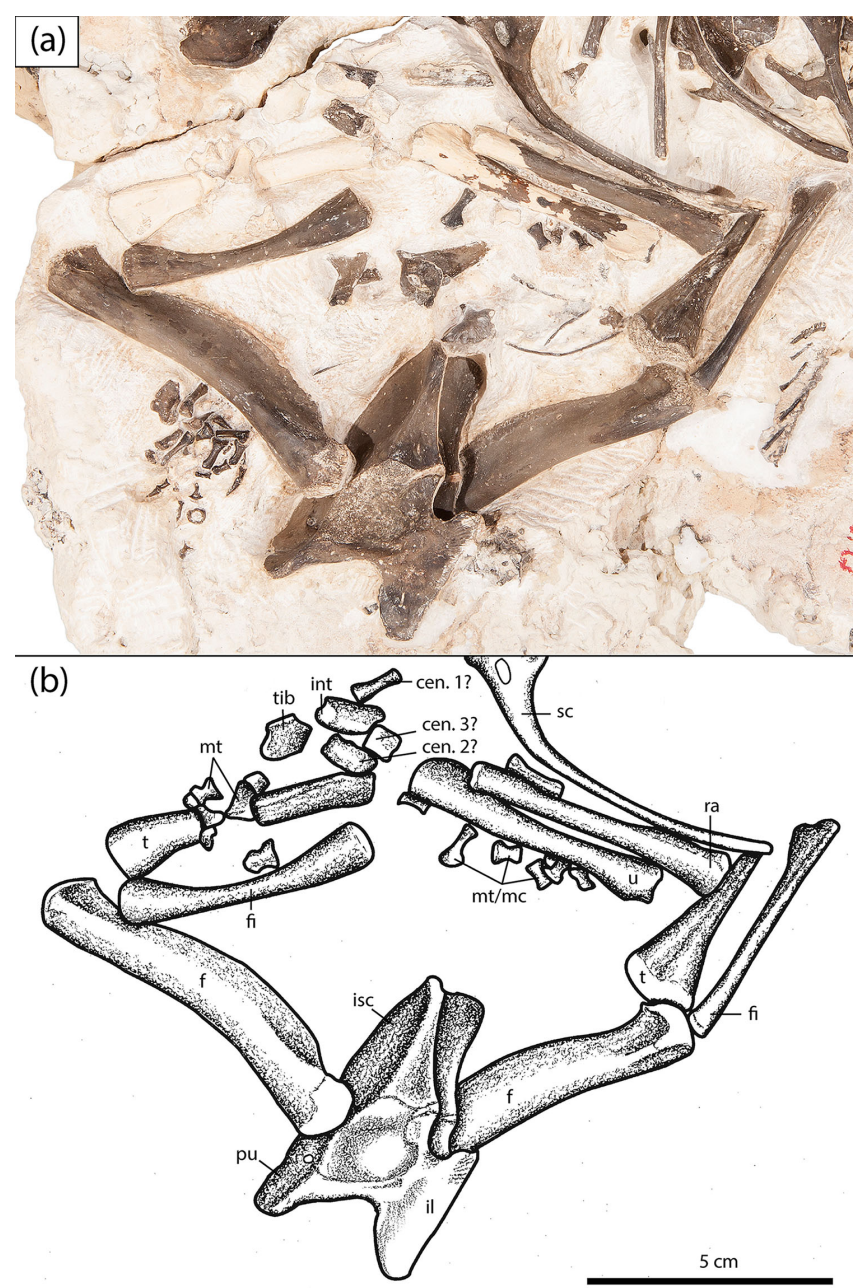

Figure 7. Close-up of the pelvic girdle and hindlimbs of the new olsoniform specimen, OMNH 73522b. (a) Photograph, (b) illustration. Abbreviations: cen, centrale; f, femur; fi, fibula; fib, fibulare; il, ilium; int, intermedium; is, ischium; mc, metacarpal; mt, metatarsal; p, pubis; ra, radius; sc, scapulacoracoid; t, tibia; tib, tibiale; u, ulna.

and the dorsal margin of the ischium is concave and without a kink (Berman et al., 1985). In Broiliellus brevis, the angle of the plate cannot be well-defined; it does feature a slight kink at the notch but without any concavity of the dorsal margin (Carroll, 1964). The pelvis of Fayella features a convex margin of the pubis, a nearly horizontal plate, and a concave dorsal margin of the ischium without a prominent kink (Olson, 1972). Lastly, in Dissorophus, the dorsal pubic margin is very slightly convex and then very slightly concave, the pubioischiadic plate is nearly horizontal, and the dorsal ischiadic margin is markedly concave and without a kink (DeMar, 1968).

\subsubsection{Hindlimb elements}

Two gracile femora are exposed in lateral profile in articulation with the pelvis of OMNH 73522b (Fig. 7). Both are iden- tical to slightly larger, isolated femora from Richards Spur that were assigned to Cacops sp. by Sullivan et al. (2000). The femoral morphology of OMNH 73522b and Cacops is distinguished from that of the co-occurring Acheloma by a slightly expanded proximal end that is deflected anteriorly, a slightly curved shaft, a prominent adductor crest, and a small fourth trochanter. The femur of Acheloma is also slightly stockier than that of Cacops. The intertrochanteric fossa is shallow in OMNH 73522b and in Cacops; neither the popliteal space nor the intercondylar fossa are exposed in this specimen.

Among olsoniforms, the femur is known from a sparse number of taxa and is not well-described or well-illustrated in most. DeMar (1968) noted that the femur of Dissorophus was similar to that of Acheloma cumminsi and differed from that of Cacops in having a thicker fourth trochanter and less starkly divided articular heads for the tibia. Williston (1914) noted that the femur of Broiliellus texensis is more robust than in Cacops. Femora of B. brevis and Brevidorsum are highly fragmentary (Carroll, 1964). Aspects of the adductor crest and the trochanter are comparable in Fayella, but the femur has also been compressed to a degree (Olson, 1972). The femur of Ecolsonia features a thicker adductor crest than in Cacops and in OMNH 73522b. The femur of A. dunni is identical to A. cumminsi (Polley and Reisz, 2011) and is distinguished from OMNH 73522b on the basis of the same features listed above from Sullivan et al. (2000).

Two fibulae are present in association with the femora of OMNH 73522b; they are slightly shorter than the associated tibiae (Fig. 7). The right fibula is exposed in an angled extensor profile and the left fibula in posterior profile. A very slight anterior fibular ridge, represented by a small convexity along the margin, is present on the proximal head of the left fibula. The shaft is cylindrical and constricted, with a very slight curvature of the posterior margin and a more pronounced curvature of the anterior margin. A very slight depression is found at the distal end near the posterior margin. The proximal head of the right fibula narrows into the shaft to form a narrow extensor ridge. A slight fibular sulcus is present on the flexor surface of the distal end, where the two facets are demarcated. The fibula of OMNH 73522a is only preserved distally in extensor profile (Fig. 6). It is larger and with a less pronounced division of the facets than that in OMNH 73522b. The shaft narrows to the same cylindrical cross-section, and the shallow groove seen in the right fibula is present.

Fibulae are rare among olsoniforms. The morphology in OMNH 73522b is identical to that of Cacops aspidephorus (Williston, 1910). DeMar (1968) noted that the fibula of Dissorophus is nearly identical to that of Cacops. Williston (1914) only noted the presence of a fibula in Broiliellus texensis. The fibulae of Ecolsonia and Acheloma are similar to that of Cacops but with a blockier proximal end and a more developed anterior fibular ridge (Olson, 1941; Berman et al., 1985; Polley and Reisz, 2011). The fibula of Tambachia is 
proportionately stockier than that of other trematopids and features the same differential morphology (Sumida et al., 1998).

Two tibiae are present in articulation with the fibulae and the femora of OMNH 73522b (Fig. 7). The right tibia is exposed in anterior profile, while the left tibia is exposed in flexor profile with only the proximal region exposed. The left tibia narrows significantly at the shaft, which features a small fossa for the insertion of the pubioischiotibialis. This fossa is framed by the posterior and anterior fibular flexor crests, which continue distally over the exposed region. In anterior profile, the right tibia is only slightly narrower at the shaft and is not expanded distally. The distal facets are not welldefined because of overlying elements. The slightly elevated anterior profile of the cnemial crest is found on the proximal head. The tibia associated with the pes of OMNH 73522a is interlayered within the rib cage and is exposed in extensor profile (Figs. 1-2, 6). It is relatively slender and notably longer than the tibiae of OMNH 73522b. As each tibia is exposed in a different profile, further comparison is not possible. The proximal end is found at the edge of the block but is not well-defined because of uneven coloration. The cnemial trough is present, and the articular surfaces are unfinished. The cnemial crest continues down the length of the shaft, which is slightly torqued. The distal end is only slightly expanded and forms a rounded knob with the intermedial facet.

The tibia of OMNH $73522 \mathrm{~b}$ is nearly identical to that of Cacops aspidephorus; the only difference is that the margins appear more sinuous in the latter in lateral profile (Williston, 1910: pl. 14). The tibia of OMNH 73522a is also comparable to that of $C$. aspidephorus, but it is proportionately much longer than in that taxon. The tibia of Dissorophus was simply noted to be identical to that of Cacops (DeMar, 1968). Nothing can be made of the figures of the tibia in Brevidorsum (Carroll, 1964: fig. 16B) or the description of Broiliellus texensis (Williston, 1914). Descriptions and figures of the element in trematopids are similarly uninformative. The tibia of Acheloma cumminsi is not figured and is described only briefly (Williston, 1909). That of $A$. dunni appears to be stockier, with a shorter shaft and a more broadly expanded proximal head (Polley and Reisz, 2011). No differences can be identified from the short description of Tambachia (Sumida et al., 1998). Only the proximal end is known in Ecolsonia, and it does not deviate from the typical olsoniform morphology (Berman et al., 1985).

\subsubsection{Miscellaneous pes and manus}

In addition to the pes described above, a large number of elements pertaining to either the manus, the carpus, or both are present near the right forelimb of OMNH 73522a and the right hindlimb of OMNH 73522b (Fig. 7). Only tentative characterizations can be provided because of the disarticulation and exposure in tilted profiles, the limited comparative material, and the possibility that they may be divided be- tween two individuals of differing taxonomy. It is more likely that they pertain to the pes, as the majority are concentrated around the distal region of the hindlimbs of OMNH 73522b and the proximal region of the forelimbs of OMNH 73255a. Most of the bones overlying the right tibia are white in coloration and appear to be the distalmost metatarsals or metacarpals. A number of short, modestly constricted elements adjacent to the ulna are more proximal metatarsals or metacarpals. A total of six larger elements are found, one below the radius that was partially damaged during preparation and is mostly unexposed, and five that are found adjacent to the fracture plane near the distal end of the tibia and the proximal end of the forelimb. A slender white bone is most likely centrale 1 of the pes, although a distal metacarpal cannot be excluded. A square white bone is most likely centrale 3 of the pes. The pentagonal white bone is tentatively identified as a tibiale based on a comparison to that of the articulated pes of OMNH 73522a. The elongate piebald-coloured element is most likely the intermedium. The black element is more indeterminate; it is most likely to be one of the central tarsals, possibly centrale 2 .

\section{Discussion}

\subsection{Taxonomic assignment}

There is little doubt that the materials described here can be referred to two, likely distinct members of the Olsoniformes. The long scapulacoracoid and the dorsal coverage of the element by the cleithrum are synapomorphies relevant to the individual preserved in the anterior trunk region (OMNH 73522a) (Schoch, 2013; Dilkes, 2015). The relative height and orientation of the iliac shaft are synapomorphies relevant to the individual preserved in the posterior trunk region (OMNH 73522b) (Schoch, 2013; Dilkes, 2015). The referral of OMNH 73522a to the Dissorophidae is based on the absence of a supinator process (present in trematopids). The absence of osteoderms, a dissorophid synapomorphy, is interpreted as a taphonomic artifact because the vertebral column is certainly significantly disturbed. If the osteoderms were attached via ligaments, as in dissorophines, they may have been more easily dislodged during preservation. Proportionately tall neural spines, seen in OMNH 73522a, have been cited as a dissorophid synapomorphy, but this may be an ontogeny-dependent trait, as short spines are known in $\mathrm{Ca}$ cops morrisi and Broiliellus (Schoch, 2012; Gee and Reisz, 2018). There are no other formal characters that would further resolve the taxonomy of either new specimen. For most elements, a combination of (1) rare preservation (e.g., pes), (2) morphological conservatism (e.g., radius), and (3) taphonomic damage when preserved (e.g., pelvis) limit any attempts to draw basic conclusions regarding the relative influence of ontogeny, intraspecific variation, and interspecific variation. 
Our interpretation of OMNH 73522a is that it can be reasonably referred to the Dissorophinae on the basis of finished tips of the neural spines (Fig. 5), not seen in eucacopines, and the presence of an open notochordal canal of the atlas, known in Dissorophus, but absent in the co-occurring Cacops (Williston, 1910; DeMar, 1968). The absence of any osteoderms likely resulted from a lack of fusion to the spines, as seen in dissorophines. Although the osteoderms remain unfused in small, immature eucacopines (Gee and Reisz, 2018), this individual is of a large size, comparable to specimens of Cacops aspidephorus in which the osteoderms are fused (Dilkes, 2009). It is much larger than specimens of C. morrisi, in which the tips of the spines have characteristically unfinished bone (Gee and Reisz, 2018). Furthermore, the spines of OMNH 73522a are covered by finished bone, indicating that any osteoderms were probably attached by soft tissue (a dissorophine feature) rather than by fusion (a eucacopine feature). Based on this interpretation, OMNH 73522a represents the first documented occurrence of a member of the Dissorophinae at Richards Spur. Of the dissorophines, only Dissorophus and Broiliellus reiszi preserve an appreciable amount of anterior postcrania and neither shows indisputable affinity with this specimen. The spines of $B$. reiszi are proportionately taller, and little information is available regarding the partial humerus and scapulacoracoid (Holmes et al., 2013). The height of the spines in Dissorophus is more comparable to OMNH 73522a (DeMar, 1968; Dilkes, 2009). However, the tips of the spines in Dissorophus feature a deep median groove for the ventral flange of the internal osteoderm rather than the laterally offset one seen in OMNH 73522a. Furthermore, figures of the uncinate processes of Dissorophus (DeMar, 1968: fig. 12) indicate that the processes project posterodorsally, rather than at a right angle to the shaft; no connecting flange or curvature of the ribs is described. The expansion of the proximal rib heads is also greater in OMNH 73522a than in Dissorophus (DeMar, 1968). Lastly, the limbs are more gracile than those figured for Dissorophus.

OMNH 73522b can only be tentatively referred on the basis of qualitative differentiation with respect to slight variation in the pelvic girdle and the femoral morphology. The girdle is most comparable to that of Cacops aspidephorus in having a pubioischiadic plate sloping at an angle intermediate to the vertical plate of Acheloma and the near-horizontal plate of Dissorophus, a dorsal pubic margin that is mostly straight and then concave near the ventral margin, and a dorsal ischiadic margin marked by an outward kink at the supracetabular notch (Fig. 7). In all regards, the femur is identical to that of Cacops sp. (Sullivan et al., 2000) and to that of Cacops aspidephorus (Williston, 1910). The unique combination of a weakly developed trochanter and a thin, deflected adductor crest shared between OMNH 73522b and Cacops further supports this tentative referral. The development of the trochanter and the deflection of the adductor crest are two of the features that readily differentiate it from
Acheloma. As girdles and complete femora are not known from all taxa, it is impossible to conclusively rule out other taxa, but no differences from the skeleton of Cacops are identified in OMNH 73522, and thus we refer it to cf. $\mathrm{Ca}$ cops. Given that the cranium of $C$. woehri appears to be of a smaller size and a more gracile architecture than $C$. morrisi, it is possible that OMNH 73522 b may belong to that species. Nevertheless, it is possible that one or both individuals could be a novel taxon, although this is more likely with regard to OMNH 73522a, which does not conform as strongly to a known taxon. Additionally, the tentative referral of OMNH 73522b is based on the similarity of the specimen to Cacops. If dissorophids, or at least eucacopines, are highly conserved in the postcranial region, then the possibility of it pertaining to a novel taxon should also be considered. However, it would be premature to designate this material as a new taxon given the absence of phylogenetically informative features.

\subsection{Implications for dissorophid postcranial anatomy}

The most interesting feature of this specimen is the anatomy of the uncinate processes. These are present in several dissorophids but with a reduced morphology comprised only of a short, posteriorly directed spike. The presence of a process that angles posteriorly at a right angle and then dorsally at nearly a right angle coupled with the size of the specimen is unique. Interestingly, the relatively large size of OMNH 73522a could indicate that the uncinate processes may be ontogenetically variable, becoming gradually more developed throughout ontogeny. It is also possible that there is some taxonomic utility associated with the morphology of the processes, in particular the development of a ventral connecting flange. If the uncinate processes served to augment the osteoderms in increasing the rigidity of the vertebral column, they may represent the plesiomorphic condition for dissorophids, as suggested by Berman and Lucas (2003). However, because uncinate processes are found in a variety of phylogenetic distant temnospondyls of various ecologies that lack osteoderms or comparable dermal ossifications (e.g., eryopiformes, metoposaurids), more work is necessary to characterize their evolutionary significance in various temnospondyl clades. The preservation of a nearly complete and articulated pes is also important in providing additional data regarding this region of the skeleton. Although the phylogenetic utility is presently limited at lower taxonomic levels, the pes described here contributes new information pertaining to interspecific variation among olsoniforms because it is distinct from those of both Dissorophus and Acheloma. Its characterization may prove useful in the future, pending additional discoveries and studies of the carpus and tarsus of temnospondyls.

Beyond these regions, many of the postcranial elements associated with OMNH 73522 are difficult to distinguish from those of other dissorophids. It is possible that the 
postcranial skeleton is highly conserved within the dissorophids, with the exception of the osteoderms, and to a lesser degree, features of the vertebrae that are associated with articulation of the osteoderms. It is also possible that there are informative features that could further resolve phylogenetic relationships but that are currently overlooked in the absence of well-preserved material. There may also be ontogenetic changes (e.g., limb proportions) that cannot be determined in the absence of growth series for most taxa. The fragmentary or poor preserved condition of most previously studied dissorophid postcranial material (not reappraised by us) as is apparent from the literature (generally fragmentary or poorly-preserved) suggests that a re-evaluation of previously published specimens may not significantly inform this uncertainty. Possible exceptions are taxa with relatively complete skeletons, such as Cacops aspidephorus and Dissorophus multicinctus (Williston, 1910; DeMar, 1968).

Additional discoveries of comparably complete and wellpreserved material, such as OMNH 73522, are the most likely source of novel data that would contribute to this discussion. For example, a comparison of the postcrania of the co-occurring C. morrisi (Gee and Reisz, 2018) and C. woehri (presently unknown) could offer some preliminary insights into the degree of variation within Cacops. The presence of two eucacopines at the Richards Spur locality with distinct cranial morphologies has led to the hypothesis that they may have been ecologically distinct to a certain degree (Fröbisch and Reisz, 2012; Fröbisch et al., 2015), and there may be corresponding differences in the postcrania. If the two taxa can be differentiated in the postcranial region, this would suggest that there is a greater range of morphology than is presently recognized.

\section{Conclusions}

Here we have described significant amounts of wellpreserved postcrania pertaining to two dissorophid taxa, one referred to cf. Cacops, and the other to the subfamily Dissorophinae. The latter specimen represents the first report of a dissorophine at the Richards Spur locality, thereby expanding the known temnospondyl diversity at the locality, as previously, the dissorophids were represented only by eucacopines Cacops morrisi and C. woehri (Reisz et al., 2009; Fröbisch and Reisz, 2012). Dissorophines, represented by several species of Broiliellus and Dissorophus multicinctus, are known almost exclusively from Texas $-B$. reiszi is known from New Mexico - and the first record of the clade at Richards Spur expands their biogeographic range. The complete pelvic girdle and articulated forelimbs expand the known morphology of the Richards Spur eucacopines, which are predominantly known only from cranial material. This material and the comparative description presented here improve our knowledge of dissorophid postcranial anatomy and variation, and provide an excellent addition to the exist- ing foundation for future studies, in particular for the phylogenetic significance, function, and ontogeny of uncinate processes, and of the pes. Further research may help to determine whether an apparent high degree of morphological conservatism in the postcranial skeleton of dissorophids is an accurate reflection of similar selection pressures for terrestriality within the clade, or if historic inattention has simply resulted in an artificial perception of such conservatism.

Data availability. All data pertaining to this study are contained within the paper.

Author contributions. RRR acquired the specimen and funding. BMG prepared the manuscript and produced figures. BMG and RRR contributed to editing of the manuscript.

Competing interests. The authors declare that they have no conflict of interest.

Acknowledgements. We thank Diane Scott (University of Toronto Mississauga) for photographs, assistance with figures, and preparation of the specimen and Mark MacDougall (University of Toronto Mississauga) for preparation of the specimen. Thanks to William May, Richard Cifelli, and the staff at the Sam Noble Oklahoma Museum of Natural History for their continued support of our work on the Richards Spur assemblage. Thanks to Nadia Fröbisch, an anonymous reviewer, and the editor, Johannes Müller, for their constructive comments that improved this manuscript. This work was supported by a NSERC Discovery Grant to RRR and the University of Toronto.

Edited by: Johannes Müller

Reviewed by: Nadia Fröbisch and one anonymous referee

\section{References}

Anderson, J. S. and Bolt, J. R.: New information on amphibamids (Tetrapoda, Temnospondyli) from Richards Spur (Fort Sill), Oklahoma, J. Vertebr. Paleontol., 33, 553-567, 2013.

Berman, D. S. and Lucas, S. G.: Aspidosaurus binasser (Amphibia, Temnospondyli), a new species of Dissorophidae from the Lower Permian of Texas, Ann. Carnegie Mus., 72, 241-262, 2003.

Berman, D. S., Reisz, R. R., and Ebert, D. A.: Ecolsonia cutlerensis, an Early Permian dissorophid amphibian from the Cutler Formation of north-central New Mexico, New Mexico Bureau of Mines and Mineral Resources, 191, 5-31, 1985.

Berman, D. S., Henrici, A. C., Martens, T., Sumida, S. S., and Anderson, J. S: Rotaryus gothae, a new trematopid (Temnospondyli: Dissorophoidea) from the Lower Permian of Central Germany, Ann. Carnegie Mus., 80, 49-65, 2011.

Bolt, J. R.: Lissamphibian origins: possible protolissamphibian from the Lower Permian of Oklahoma, Science, 166, 888-891, 1969. 
Carroll, R. L.: Early evolution of the dissorophid amphibians, Bulletin of the Museum of Comparative Zoology, 131, 161-250, 1964.

Case, E. C., Wiliston, S. W., and Mehl, M. G.: Permo-Carboniferous vertebrates from New Mexico, Carnegie Institute of Washington Publication, 181, 1-81, 1913.

Clack, J. A. and Milner, A. R.: Morphology and systematics of the Pennsylvanian amphibian Platyrhinops lyelli (Amphibia: Temnospondyli), Earth Env. Sci. T. R. So., 100, 275-295, 2010 (for 2009).

Daly, E.: The Amphibamidae (Amphibia: Temnospondyli), with a description of a new genus from the Upper Pennsylvanian of Kansas, The University of Kansas Museum of Natural History Miscellaneous Publications, 85, 1-59, 1994.

DeMar, R. E.: The Permian labyrinthodont amphibian Dissorophus multicinctus, and adaptations and phylogeny of the family Dissorophidae, J. Paleontol., 42, 1210-1242, 1968.

Dilkes, D.: Comparison and biomechanical interpretations of the vertebrae and osteoderms of Cacops aspidephorus and Dissorophus multicinctus (Temnospondyli, Dissorophidae), J. Vertebr. Paleontol., 29, 1013-1021, 2009.

Dilkes, D. and Brown, L. E.: Biomechanics of the vertebrae and associated osteoderms of the Early Permian amphibian Cacops aspidephorus, J. Zool., 271, 396-407, 2007.

Dilkes, D. W.: A new trematopsid amphibian (Temnospondyli: Dissorophoidea) from the Lower Permian of Texas, J. Vertebr. Paleontol., 10, 222-243, 1990.

Dilkes, D. W.: Carpus and tarsus of Temnospondyli, Vertebrate Anatomy Morphology Paleontology, 1, 51-87, 2015.

Fröbisch, N. B. and Reisz, R. R.: A new Lower Permian amphibamid (Dissorophoidea, Temnospondyli) from the fissure fill deposits near Richards Spur, Oklahoma, J. Vertebr. Paleontol., 28, 1015-1030, 2008.

Fröbisch, N. B. and Reisz, R. R.: A new species of dissorophid (Cacops woehri) from the Lower Permian Dolese quarry, near Richards Spur, Oklahoma, J. Vertebr. Paleontol., 32, 35-44, 2012.

Fröbisch, N. B., Brar, A., and Reisz, R. R.: New specimen of Cacops woehri indicates differences in the ontogenetic trajectories among cacopine dissorophids, Foss. Rec., 18, 73-80, https://doi.org/10.5194/fr-18-73-2015, 2015.

Gee, B. M. and Reisz, R. R.: Cranial and postcranial anatomy of $\mathrm{Ca}$ cops morrisi, a eucacopine dissorophid from the Early Permian, J. Vertebr. Paleontol., in press, 2018.
Holmes, R., Berman, D. S., and Anderson, J. S.: A new dissorophid (Temnospondyli, Dissorophoidea) from the Early Permian of New Mexico (USA), C. R. Palevol., 12, 419-435, 2013.

Langston, W.: Permian amphibians from New Mexico, University of California, Publications in Geological Sciences, 29, 349-416, 1953.

Olson, E. C.: The family Trematopsidae, J. Geol., 49, 149-176, 1941.

Polley, B. P. and Reisz, R. R.: A new Lower Permian trematopid (Temnospondyli: Dissorophoidea) from Richards Spur, Oklahoma, Zool. J. Linn. Soc-Lond., 161, 789-815, 2011.

Reisz, R. R., Schoch, R. R., and Anderson, J. S.: The armoured dissorophid Cacops from the Early Permian of Oklahoma and the exploitation of the terrestrial realm by amphibians, Naturwissenschaften, 96, 789-796, 2009.

Schoch, R. R.: Character distribution and phylogeny of the dissorophid temnospondyls, Foss. Rec., 15, 121-137, https://doi.org/10.1002/mmng.201200010, 2012.

Schoch, R. R.: The evolution of major temnospondyl clades: an inclusive analysis, J. Syst. Palaeontol., 11, 673-705, 2013.

Schoch, R. R. and Sues, H.-D.: A new dissorophid temnospondyl from the Lower Permian of north-central Texas, C. R. Palevol., 12, 437-445, 2013.

Sigurdsen, T. and Bolt, J. R.: The Lower Permian amphibamid Doleserpeton (Temnospondyli: Dissorophoidea), the interrelationships of amphibamids, and the origin of modern amphibians, J. Vertebr. Paleontol., 30, 1360-1377, 2010.

Sullivan, C., Reisz, R. R., and May, W. J.: Large dissorophoid skeletal elements from the Lower Permian Richards Spur fissures, Oklahoma, and their paleoecological implications, J. Vertebr. Paleontol., 20, 456-461, 2000.

Sumida, S. S., Berman, D. S., and Martens, T.: A new trematopid amphibian from the Lower Permian of central Germany, Palaeontology, 41, 605-629, 1998.

Williston, S. W.: New or little-known Permian vertebrates: Trematops, new genus, J. Geol., 17, 636-658, 1909.

Williston, S. W.: Cacops, Desmospondylus; new genera of Permian vertebrates, Geol. Soc. Am. Bull., 21, 249-284, 1910.

Williston, S. W. (Ed.): American Permian Vertebrates, University of Chicago Press, Chicago, 145 pp., 1911.

Williston, S. W.: Broiliellus, a new genus of amphibians from the Permian of Texas, J. Geol., 22, 49-56, 1914. 